\title{
Survey of attitudes, materials and methods preferred in root canal therapy by general dental practice in Turkey: Part 1
}

\author{
Gul Celik Unal' \\ Bulem Ureyen Kaya' \\ Ali Gurhan Tac' \\ Ayse Diljin Kececi'
}

\begin{abstract}
Objective: To gather information on the materials and methods employed in root canal treatment by dentists in Turkey.

Methods: A questionnaire was distributed to 1,527 dentists who attended the Turkish Dental Association Congress. Respondents were asked to choose one or more suitable answers for the questions. Data was gathered for demographic and professional information regarding stages, materials, and methods commonly used in endodontic therapy. The collected data was analyzed using the statistical package SPSS. Descriptive statistics were given as frequencies (n) and percent (\%). Chisquare $\left(\chi^{2}\right)$ test was used to investigate the influence of gender and the years of professional activity for the materials and techniques employed.

Results: The response rate was $49 \%$. A total of $97 \%$ of respondents were working in a general dental practice. Of respondents, $44 \%$ were using an agent containing arsenic or aldehyde. Only $5.1 \%$ of the respondents preferred the rubber dam isolation method. Sodium hypochlorite was the most popular choice $(73 \%)$ as a root canal irrigation solution. Calcium hydroxide was the most commonly used medicament (53\%). Most of the practitioners (77\%) preferred radiographs for working-length determination. Root canal preparation done solely with K-Files or in combination with other instruments was preferred by $73.1 \%$ of the respondents. $\mathrm{Ni}$-Ti hand or rotary files were used by $79.7 \%$ of the practitioners. Polymer based root canal sealers were the sealers most frequently chosen $(48.4 \%)$. The majority of the respondents $(66.2 \%)$ preferred cold lateral condensation as an obturation technique. Gender affected the preference of intracanal medicament, periapical radiographs for working-length determination, root canal instrument, root canal sealers, and root canal obturation technique $(P<.05)$. Years of professional experience affected the preference of devitalizing agents, irrigation solutions, intracanal medicament, root canal instrument, root canal sealer, and root canal obturation technique $(\mathrm{P}<.05)$.

Conclusions: It is clear that a number of dentists, irrespective of the time elapsed since their graduation, relied on techniques, and used products and materials that are currently favoured by expert opinion. Unfortunately, it was noted that some practitioners are still using arsenic- and aldehyde-containing devitalizing agents, and most did not use rubber dam as an isolation method. (Eur J Dent 2012;6:376-384)
\end{abstract}

Key words: General dental practice; questionnaire; Turkey; root canal treatment

Suleyman Demirel University, Faculty of Dentistry, Department of Endodontics, Isparta, TURKIYE
Corresponding author: Dr. Bulem Ureyen Kaya Suleyman Demirel Universitesi, Dishekimliği Fakultesi, Endodonti AD 32260 Kampus - Isparta / TURKIYE Tel: +902462113705 Fax: +902462370607 Email: bureyendhotmail.com 


\section{INTRODUCTION}

As much concern is now given to oral and tooth health around the world, the amount of money spent for tooth treatment has increased and received a larger share of the general health budget. However, Republic of Turkey the Social Security Institution stated that $2.5 \%$ of spending on health included oral and tooth health in 2008 versus $2 \%$ in 2009. ${ }^{1}$ Both the financial advantages of retaining a tooth by endodontic therapy rather than by extraction and prosthetic replacement, and the aesthetic, functional, and physiological advantages of having one's own natural tooth have increased the importance of preventive dentistry and endodontics. $^{2}$

In government hospitals and health centres of Turkey, the predominant forms of treatment are extraction, removable prosthodontics, and, in some places, routine amalgam and composite restorations. Root canal treatment is not generally preferred. The main reasons for this may be a lack of endodontic equipment and time. Therefore, most endodontic therapy is, carried out in the clinics of private dental practices or dental faculties. On the other hand, it has been reported that attendees on courses on endodontics generally wish to learn how to make endodontic treatment quicker, easier and more successful. ${ }^{3}$ Currently, the Ministry of Health in Turkey mandated that dentists working in government hospitals and health centres perform endodontic treatment.

In 2004, over one- hundred- thousand teeth were root filled in Turkey under the regulations of the Government Dental Services and the number of root-filled teeth almost doubled $(219,699)$ in 2005. Root-filled teeth increased to 524,207 in 2009.' The quality of root canal treatment is as important as its quantity. Dental schools must prepare their students to undertake uncomplicated root canal treatments of predictable quality upon graduation. Undergraduate curriculum guidelines have been formulated by the European Society of Endodontology to define the acceptable standard of care in clinical endodontics. ${ }^{4}$ Several studies, however, have reported that the majority of dentists are not in compliance with these guidelines. ${ }^{5-7}$ These studies investigated the attitude of dentists in Western countries, such as Denmark, ${ }^{7}$ UK, ${ }^{5}$ Belgium, ${ }^{6}$ and the USA. ${ }^{5}$ Other studies have investigated the attitude of general dental practitioners toward various aspects of endodontic treatment in developing countries. ${ }^{9-12}$ Few studies have investigated the attitudes of general dental practitioners in Turkey.

The purpose of this study was to gather information on the materials and methods employed in root canal treatment by dentists in Turkey, in order to evaluate and improve the quality of current practice. The scope of the study was also to determine whether gender and years of professional experience affected the choice of materials and methods.

\section{MATERIALS AND METHODS}

The questionnaire was distributed to a total number of 1,527 dentists who attended the $11^{\text {th }}$ International Dental Congress organized by the Turkish Dental Association. The data were granted solely for use in this study. An anonymous questionnaire consisting of 25 questions concerning different aspects of endodontic treatment was prepared. Nineteen of the 25 questions were selected for this article. The remaining 6 questions related to indication of single- or multi-visit root canal treatment, usage of antibiotics, -attitude of practioners towards severe pain, and large periapical lesions with or without extraoral fistula were gathered for Part 2 of the study.

The first part of the questionnaire consisted of 7 questions, which requested basic information regarding city, type of practice (i.e., private dental office or community service), age, gender, years of professional experience, and if applicable, whether a particular clinical specialty was practiced.

The second part of the questionnaire consisted of 12 questions related to the stages, materials, and methods that are typically used in endodontic therapy.

The questionnaire consisted of 19 multiplechoice questions. Respondents were informed to choose one or more suitable answers for the questions Space was provided for all questions when additional comments were necessary and, in the event that the usual practice was not adequately covered by the given choices.

Three persons were entrusted for handing out and collecting the questionnaires. The questionnaires were distrubuted and respondents were asked to return the completed questionnairs to the questionnaire staff. The questionnaire staff did not 
wait near the participants while the participants were answering questions.

The collected data were entered into a personal computer and analyzed using the statistical package SPSS 10. Descriptive statistics were given as frequencies ( $n$ ) and percents (\%). Chi-square $\left(\chi^{2}\right)$ test was used to investigate the influence of gender and the years of professional activity on the materials and techniques employed. The chosen level of significance was set at $P<.05$. Unanswered questions were treated as missing values.

\section{RESULTS}

The results are given as absolute frequencies, as well as percentages in Tables 1-6. Of the 1527 questionnaires distributed, 748 completed replies were received. The response rate was $49 \%$. Three questionnaires were discarded because the respondents did not perform endodontic treatment.

\section{Demographic and Professional Data}

Fifty-two percent (388) of the respondents practiced their profession in community services. Forty-four percent (328) were in the 31-40 yearold demographic. Fifty-one percent were males and $49 \%$ were females. Thirty-six (272) percent of respondents had 1-10 years of professional experience. Most of the (97\%) participants of the

Table 1. Demographic and professional data of the respondents.

\begin{tabular}{|c|c|c|}
\hline & Frequency $(\mathrm{n})$ & $\%$ \\
\hline \multicolumn{3}{|l|}{ Type of practice } \\
\hline Private dental office & 360 & 48,1 \\
\hline Community service & 388 & 51,9 \\
\hline Missing & 0 & 0 \\
\hline \multicolumn{3}{|l|}{ Age } \\
\hline $21-30$ & 112 & 14,9 \\
\hline $31-40$ & 328 & 43,9 \\
\hline $41-50$ & 214 & 28,6 \\
\hline$>50$ & 94 & 12,6 \\
\hline Missing & 0 & 0 \\
\hline \multicolumn{3}{|l|}{ Gender } \\
\hline Male & 382 & 51 \\
\hline Female & 366 & 49 \\
\hline Missing & 0 & 0 \\
\hline \multicolumn{3}{|l|}{ Years of professional activity } \\
\hline $1-10$ & 272 & 36,4 \\
\hline $11-20$ & 270 & 36,1 \\
\hline$>20$ & 206 & 27,5 \\
\hline Missing & 0 & 0 \\
\hline \multicolumn{3}{|l|}{ Clinical speciality } \\
\hline General dental practioners & 722 & 96,5 \\
\hline Endodontists & 8 & 1,1 \\
\hline Maxillo-facial surgery & 12 & 1,6 \\
\hline Other & 6 & 0,8 \\
\hline Missing & 0 & 0 \\
\hline
\end{tabular}

Table 2. The choice of devitalizing agents and isolation methods.

\begin{tabular}{|c|c|c|c|c|c|}
\hline Devitalizing Agents & Frequency (n) & $\%$ & Isolation Methods & Frequency (n) & $\%$ \\
\hline Nothing & 418 & 55,9 & Cotton roll & 736 & 98,4 \\
\hline Containing arsenic & 182 & 24,3 & Saliva ejector & 706 & 94,4 \\
\hline Containing aldehyde & 148 & 19,8 & Rubber dam & 38 & 5,1 \\
\hline Other & - & - & Other & - & - \\
\hline Missing & & & Missing & & \\
\hline
\end{tabular}


congress who volunteered to answer this questionnaire were general dental practitioners. Only $1.1 \%$ of the respondents defined their clinical specialties as endodontics. The distributions of the re- spondents according to demographics and professional data are shown in Table 1.

Table 3. Choice of root canal irrigation solution and intracanal medicament.

\begin{tabular}{|c|c|c|c|c|c|}
\hline Irrigation Solutions & Frequency (n) & $\%$ & Intracanal Medicament & Frequency (n) & $\%$ \\
\hline Sodium hypochlorite & 546 & 73 & Calcium hydroxide & 398 & 53,2 \\
\hline EDTA or other chelating agents & 242 & 32,4 & Chlorhexidine & 276 & 36,9 \\
\hline Distilled water or saline & 218 & 29,1 & Antibiotics & 116 & 15,5 \\
\hline Sodium hypochlorite $+\mathrm{H}_{2} \mathrm{O}_{2}$ & 190 & 25,4 & Eugenol & 88 & 11,8 \\
\hline $\mathrm{H}_{2} \mathrm{O}_{2}$ & 180 & 24,1 & Formocresol & 64 & 8,6 \\
\hline \multirow[t]{3}{*}{ Acohol } & 8 & 1,1 & Cresatin & 50 & 6,7 \\
\hline & & & Corticosteroids & 32 & 4,3 \\
\hline & & & Missing & 6 & 0,8 \\
\hline
\end{tabular}

Table 4. Choice of working length determination and preparation technique.

\begin{tabular}{|c|c|c|c|c|c|}
\hline Working Length Determination & Frequency & $\%$ & Preparation Techniques & Frequency & $\%$ \\
\hline Tactile sensation & 352 & 47,1 & Standard & 456 & 61,9 \\
\hline Ingle method & 10 & 1,3 & Step-back & 166 & 22,6 \\
\hline Electronic apex locaters & 96 & 12,8 & Crown-down & 194 & 26,4 \\
\hline Radiography & 578 & 77,3 & Rotary techniques & 164 & 22,3 \\
\hline Digital radiography & 96 & 12,8 & Anti-curvature filing & 18 & 2,4 \\
\hline Others & & & Others & & \\
\hline Missing & & & Missing & 12 & 1,6 \\
\hline
\end{tabular}

Table 5. The choice of instruments and $\mathrm{Ni}$-Ti rotary instruments.

\begin{tabular}{|c|c|c|c|c|c|}
\hline Instruments & Frequency (n) & $\%$ & $\mathrm{Ni}$-Ti rotary Instruments & Frequency (n) & $\%$ \\
\hline K- file & 402 & 54,2 & ProFile & 110 & 15,4 \\
\hline H-file & 306 & 41,2 & Hero 642 & 212 & 29,6 \\
\hline $\mathrm{K}$ - file modification & 140 & 18,9 & ProTaper & 80 & 11,2 \\
\hline $\mathrm{H}$ - file modification & 120 & 16,2 & Quantec & 8 & 1,1 \\
\hline Reamer & 86 & 11,6 & K3 & 10 & 1,4 \\
\hline Gates-Glidden / Peeso & 70 & 9,4 & Giromatic & 18 & 2,5 \\
\hline $\mathrm{Ni}$-Ti hand file & 306 & 41,2 & GT & 6 & 0,8 \\
\hline $\mathrm{Ni}$-Ti rotary file & 286 & 38,5 & None & 374 & 52,2 \\
\hline Others & & & Others & & \\
\hline Missing & 6 & 0,8 & Missing & 26 & 4,3 \\
\hline
\end{tabular}

Table 6. Choice of root canal sealer and obturation technique.

\begin{tabular}{|c|c|c|c|c|c|}
\hline Sealers & Frequency & $\%$ & Obturation Techniques & Frequency & $\%$ \\
\hline Zinc oxide eugenol based & 42 & 5,7 & Sealer alone & 134 & 18,1 \\
\hline Calcium hydroxide based & 260 & 35,1 & Silver cone & 4 & 0,5 \\
\hline Paraformaldehyde based & 312 & 42,2 & Single cone & 192 & 25,9 \\
\hline Polymers & 358 & 48,4 & Lateral condensation & 490 & 66,2 \\
\hline Glass ionomer based & 8 & 1,1 & Vertical condensation & 60 & 8,1 \\
\hline lodoform & 30 & 4,1 & Warm gutta percha & 128 & 17,2 \\
\hline Others & & & Other & & \\
\hline Missing & 8 & 1,1 & Missing & 8 & 1,1 \\
\hline
\end{tabular}




\section{Devitalizing Agent}

Forty-four percent (330) of the respondents were using devitalization agents. Of respondents, $24 \%$ (182) were using agents containing arsenic, and $20 \%$ (148) were using agents containing aldehyde. The various devitalizing agents are shown in Table 2. Forty-nine (178) percent of the females and $40 \%$ (152) of the males were using devitalizing agents, and the data showed that gender did not affect the usage of devitalizing agents ( $P>$.05). There was a statistically significant difference in the usage of agents as related to the years of professional experience $(P<.05)$. Arsenic was mostly preferred by those with 11-20 years of professional experience $(43 \%)(P<.05)$. The various devitalizing agents are shown in Table 2.

\section{Isolation Methods}

Only $5,1 \%$ (38) of the respondents preferred the rubber dam isolation method. Forty-two (16) percent and $58 \%$ (22) of the respondents using the rubber dam isolation method were females and males, respectively, and there was no statistically significant difference between them ( $P>$.05).

The various isolation methods are shown in Table 2. Years of professional experience also did not influence the preference of isolation methods (P>.05).

\section{Canal Irrigation Solutions}

Sodium hypochlorite was the most popular choice as a root canal irrigation solution, with $25 \%$ (190) of the respondents using a combination of sodium hypochlorite and hydrogen peroxide and $73 \%$ (546) using sodium hypochlorite alone during treatment (Table 3).

Gender did not significantly influence the choice of irrigation solution (P>.05). The choice of distilled water and alcohol was affected by the years of professional experience $(P<.05)$. Distilled water was mostly preferred by the group with 1-10 years of experience, while alcohol was preferred by those with $20+$ years of professional experience.

\section{Intracanal Medicaments}

Calcium hydroxide was the most commonly used medicament (53\% of respondents). The remaining practitioners used different formulations, including chlorhexidine, fenolic compounds, aldehydes, eugenol, formocresol, peroxides, antibiotics, and corticosteroids (Table 3). Only 6 respon- dents indicated that they did not use intracanal medicaments between appointments.

The choice of iodine compounds and corticosteroids was affected by the gender of the practitioner $(P<.05)$. Eighty percent of the respondents who indicated that they were using iodine compounds were females; $75 \%$ of the respondents who indicated that they were using corticosteroids were females. The practitioners' years of professional experience affected whether they chose to use chlorhexidine $(\mathrm{P}<$.05). Chlorhexidine was the least preferred medicament by those in the group with $20+$ years of professional experience.

\section{Working Length Determination}

Most of the practitioners (77\%) (578) preferred radiographs for working length determination. The use of electronic apex locaters was limited to $13 \%$ (96) of the practitioners (Table 4).

Gender affected the preference of periapical radiographs for working length determination $(P<.05)$. Fifty-four percent of the males and $46 \%$ of the female respondents indicate that they were using periapical radiographs. The years of professional experience did not statistically significantly affect practitioners' choices of working length determination.

\section{Instruments}

K-Files were the most popular instruments (54.2\%) (402). Root canal preparation done solely with K-Files or in combination with other instruments was preferred by $73.1 \%$ (542) of respondents (Table 5). Ni-Ti hand files were used by $41.2 \%$ (306) of the practitioners.

The preference of $\mathrm{Ni}$-Ti rotary files was affected by gender $(P<.05)$. Sixty-four percent $(184)$ of respondents using Ni-Ti rotary files were males.

It was found that the years of professional experience affect practitioners' use of $\mathrm{K}$ and $\mathrm{H}$ files $(\mathrm{P}<.05) . \mathrm{K}$ and $\mathrm{H}$ hand files (43\%, 54\% respectively) are mostly preferred in the group with 1-10 years of professional experience. The group with $>20$ years of professional tended to use rotary instruments more than their younger colleagues $(P<.05)$.

\section{Rotary Instruments}

Forty-nine percent (342) of the respondents use one of the rotary instruments. Hero 642 (29.60\%) was the most preferred rotary instrument (Table 5). 
There was a statistically significant difference between the genders regarding the frequency of the use of rotary instruments $(P<.05)$. Sixty-four percent of the respondents who were using ProFile $166 \%$ ProTaper, 100\% Quantec) were males. It was found that years of professional experience influences the use of rotary instruments $(P<.05)$. Of 342 respondents using rotary instruments, 140 $(41 \%)$ were in the $20+$ years of professional experience group.

\section{Root Canal Sealer}

Polymer (48\%) (358), paraformaldehyde (42\%) (312), and calcium-hydroxide-based (35\%) (260) root canal sealers were most frequently chosen (Table 6).

Females frequently use zinc oxide eugenol and calcium-hydroxide-based root canal sealers $(P<.05)$. The practitioner's years of professional experience affected the use of iodoform-based root canal sealers $(P<.05)$. Of 30 respondents using iodoform-based-sealer, only $2(7 \%)$ respondents were in the group with 1-10 years of professional experience.

\section{Obturation Technique}

The majority $(66 \%)(490)$ of the respondents preferred cold lateral condensation as an obturation technique (Table 6).

There was a statistically significant difference between the genders regarding the use of the lateral condensation technique $\mathrm{P}<.05$. Fifty-six percent of the respondents using lateral condensation technique were males. Years of professional experience affected the preference of lateral condensation, single cone, or sealer-only obturation techniques $(P<.05)$. The lateral condensation technique is mostly preferred $(47 \%)$ in the group with 1-10 years of professional experience; the single cone $(41 \%)$ is mostly preferred in the $11-20$ years group; and sealer only is preferred $(45 \%)$ in the 11 20 years group.

\section{DISCUSSION}

The cohorts selected in this study were attendees of the Turkish Dental Association's 11 $11^{\text {th }}$ International Dental Congress and may not be truly representative of the general dental population throughout Turkey. It was advantageous to use this group because they were participants of the congress and likely interested in scientific research and new technology. Our aim was to gather information about the attitudes of these dentists toward endodontics. Thus, the information gathered is still important and useful, particularly as it relates to improvements that have been introduced in dental practice.

The response rate was acceptable, which is expected when questionnaires are handed out personally and collected after completion. This is similar with postal surveys, in which the response rates are generally lower. A similar survey held by the Council of the British Endodontic Society amongst general dental practitioners in England had a low response rate of $32 \% .{ }^{13}$ Jenkins et al, ${ }^{6}$ obtained a response rate of $41 \%$ but, limited their survey to practitioners who had graduated from one dental school. Slaus and Bottenberg ${ }^{7}$ obtained a response rate of $25 \%$ amongst all Flemish dentists.

Rubber dam isolation is considered the standard of care in endodontics. Unfortunately, the use of rubber dam by Turkish dental practitioners was low and only $5.1 \%$ of the practitioners used rubber dam in all cases. There was no relation between the use of rubber dam and the time elapsed after graduation, indicating that its use in daily dental practice is quickly abandoned. These results agree with other recent studies. Al-Omari ${ }^{12}$ reported that none of the dentists were routinely using rubber dam to isolate the field of operation during root canal therapy. Practitioners may equate rubber dam use with time loss, patient pain, extra cost, frustration, and irritation. ${ }^{14}$ Lynch and McConnell ${ }^{15}$ reported that this lack of use presents certain medico-legal, safety and treatment quality concerns for the profession. Peciuliene et $\mathrm{al}^{16}$ reported that of the respondents $66 \%$ never used a rubber dam. In Belgium, $64.5 \%$ of practitioners did not use rubber dam routinely during root canal treatment ${ }^{7,23}$ and only $3.4 \%$ of them reported using rubber dam as a standard procedure. ${ }^{7}$ A survey amongst American general dental practitioners showed that $59 \%$ of respondents always used rubber dam. ${ }^{17}$ In Turkey, endodontic dentistry does not have a specific approach regarding application techniques. To promote the use of rubber dam, especially in countries with a high population, rather than thru legal arrangements, our thoughts are that an emphasis in education and increased awareness of the im- 
portance and weight of this issue are the best approaches. The most effective approaches would be to increase the awareness of practitioners regarding the importance of rubber dam, and by increasing educational awareness at the undergraduate and continuing education levels.

In this study, sodium hypochlorite was the most popular root canal irrigant. Aqueous sodium hypochlorite solution $(0.5-5.25 \%)$ is the current gold standard irrigant solution, combining profound antimicrobial and soft-tissue solvent activity. ${ }^{18,19}$ Sodium hypochlorite combined with hydrogen peroxide and chlorhexidine has been described in the literature. ${ }^{2}$ Furthermore, the use of irrigants such as chloramine and saline are not recommended for endodontic use, ${ }^{20}$ as they do not have the antimicrobial and tissue-solving capacities of a sodium hypochlorite solution. In this study, $29.1 \%$ of the respondents used distilled water or saline. Hommez et $\mathrm{al}^{23}$ and $\mathrm{Al}-0$ mari ${ }^{12}$ stated that a possible reason for not using sodium hypochlorite instead of a weak solution was the limited use of rubber dam. 6,21,22 Calcium hydroxide is recommended as the standard intracanal dressing in root-canal treatment. ${ }^{24,25}$ In the present study, calcium hydroxide was used by $53 \%$ of the respondents and, it was mainly employed by younger practitioners, which is considerably more than the $21.1 \%$ in the study by Saunders et al, ${ }^{21}$ the $7 \%$ in the study by Jenkins et $\mathrm{al}^{6}$ in the UK, the $6.8 \%$ in the study by Ahmed et $\mathrm{al}^{11}$ in Sudan, the $11.5 \%$ in the study by Al-Omari, ${ }^{12}$ or the $9 \%$ in the USA. ${ }^{9}$ However, in Dutch $^{26}$ and Flemish studies, ${ }^{7}$ the percentage of respondents using calcium hydroxide was $86.2 \%$ and $64.6 \%$, respectively.

Chlorhexidine has been recommended as a root canal irrigant because of its broad antibacterial spectrum, biocompatibility, and substantivity. ${ }^{27-29}$ It was pleasant to learn that the second most popular choice for an interappointment medicament was chlorhexidine. Chlorhexidine was the least preferred medicament by those in the group with $20+$ years of professional experience.

Biocompatible dressings such as calcium hydroxide pastes are favoured..$^{30}$ However, it has been previously reported that only a few dentists (7-10\%) routinely used non-setting calcium hydroxide as their interappointment medicament. ${ }^{6,7}$ In the present study, although calcium hydroxide was the most popular choice with $53.2 \%$ using it to dress the root canal system between visits, unfortunately, caustic and organic root-canal disinfectants were used by an important number of the respondents (Table 2 and 3). These products contain organic components such as paraformaldehyde, chlorophenol, parachloromonophenol, creosote, arsenicum anhydride, and iodoform. It has been argued that most of these products should be prohibited, as they are highly toxic, allergenic, mutagenic, carcinogenic, and harmful to patients. ${ }^{31}$ It has been shown that some of these products caused periodontal destruction and delayed healing of periapical tissues. ${ }^{23,32-34}$ It was worrisome that the use of caustic agents in this study was limited in intracanal medications; however, it was seen that these caustic agents, such as arsenic, were still being used as devitalizing agents.

The determination of the apical limit for instrumentation and obturation is one of the most important steps in root canal treatment, and it has been a challenge in endodontics. Many studies suggest that performing the root canal treatment at a proper length is a predictor for a successful outcome. ${ }^{35}$ In the present study, periapical radiography was the method favoured for working length estimation by the majority of respondents (77\%). Furthermore, electronic apex locators are claimed to be more reliable than radiographs for identifying the working-length of the root canal. ${ }^{36}$ The recommendation today is that working-length determination should be carried out using a combination of an apex locator and radiography. ${ }^{37}$ In the current study, the use of electronic apex locaters was done by only $12.8 \%$ of the practitioners. The use of tactile sensation to determine workinglength cannot be recommended because the instruments may bind against the canal walls at any position along their length ${ }^{38}$ or perforate apically. ${ }^{6}$ It was disappointing that a majority $(47.1 \%)$ of the respondents relied on tactile sensation for estimation of working-length.

$\mathrm{K}$-files and $\mathrm{H}$ files were the most favoured hand instruments for root canal preparation. Reamers were used by more than half of the Flemish dentists $^{7}$ in 1997, but their use was limited to $11.6 \%$ in this study. It was encouraging that use of $\mathrm{Ni}-\mathrm{Ti}$ rotary files as well as hand files was more popular than in the other studies. ${ }^{7,12,23}$ Generally, dentists in Jordan ${ }^{12}$ tend to use hand instruments and are not inclined to use more advanced engine-driven tech- 
niques for shaping the root canal system. It was remarkable that these advanced engine-driven techniques were generally preferred by older dental practitioners in this study. This may be due to the high cost of these systems for younger dental practitioners. Preparation techniques, such as the crown-down technique, the balanced-force technique, the crown-down pressureless technique, or the modified double-flared technique were not commonly used and were only known by a minority of the practitioners. This finding emphasizes the need for continuing postgraduate training in endodontics. Koch et al $^{39}$ reported that GDPs who had undergone an educational programme in $\mathrm{Ni}$ Ti rotary instrumentation had successfully integrated the technique into daily clinical practice. In addition, a more important measure to be taken to encourage practitioners to use advanced endodontic systems is to devise a system to economically support young practitioners by making these systems more affordable. Such measures should be adopted and supported by Turkish Dental Associations and the private sector.

Over the years, numerous methods have been advocated to obturate the prepared root-canal system, each with their own claims of ease, efficiency, or superiority. Most general dental practitioners $(66.2 \%)$ use lateral condensation as an obturation technique. It is a relatively simple and versatile technique that does not require expensive equipment. It is, therefore, not surprising that it is the technique used by the majority of responding practitioners lespecially the younger ones) in their general practice. Single-cone/point techniques cannot reliably fill all of the root canal space in three dimensions and are not recommended. However, $25.9 \%$ of the dentists in the current survey use a single cone technique, as did $68 \%$ of Swiss dentists ${ }^{40}$ and $31.3 \%$ in Jordan. ${ }^{12} \mathrm{Ad}-$ ditionally, $18.1 \%$ of respondents use only paste to obturate the root canal system; $12.2 \%$ do so in Jordan ${ }^{12}$ This is particularly problematic with paraformaldehyde-based sealers, as they can cause extensive damage to the periradicular tissues when extruded. ${ }^{41,42}$ The most popular root-canal sealer amongst our general dental practitioners was polymer-based root canal sealers $(48.4 \%)$ similar to the results of Slaus and Bottenberg. ${ }^{7}$ Seemingly, dentists in North Jordan are not strong advocates of the more recently introduced warm gutta per- cha techniques. This may be attributed to the additional cost involved or the lack of skill and training. ${ }^{12}$

\section{CONCLUSION}

The cohorts selected in this study attended a dental congress and may not be truly representative of the general dental population throughout Turkey. However, we collected the attitudes of this group toward new technology in endodontics. It is noted that a group of dentists, irrespective of the time since graduation, relies on techniques and use products and materials which are currently favoured by expert opinion. Unfortunately, it was also noted that some of the practitioners are still using arsenic- and aldehyde-containing devitalizing agents, and most of them did not use rubber dam as an isolation method. In Turkey, there are many dental schools that offer postgraduate training in endodontics, and quite number of courses are available that covernew endodontic technologies and materials. Thus, the standard of care for endodontics can be improved by increasing general dental practitioner interest in pursuing postgraduate education.

\section{REFERENCES}

1. http://212.175.169.241/baf/informationmanagement/ControlMail.aspx

2. Ingle JI, Bakland LK. Endodontics, 4th edn. Malvern, PA, USA:Williams \&Wilkins 1994.

3. Carrotte PV. Current practice in endodontics. Dent Update 2000;27:338-340

4. European Society of Endodontology. Undergraduate curriculum guidelines Undergraduate Curriculum Guidelines for Endodontology. Int Endod J 2001;34:574-580.

5. Whitten BH, Gardiner DL, Jeansonne BG, Lemon RR. Current trends in endodontic treatment: report of a national survey. J Am Dent Assoc 1996;127:133-141.

6. Jenkins SM, Hayes SJ, Dummer PM. A study of endodontic treatment carried out in dental practice within the UK. Int Endod J 2001;34:16-22

7. Slaus G, Bottenberg P. A survey of endodontic practice amongst Flemish dentists. Int Endod J 2002;35:759-767

8. Bjørndal $L$, Reit $C$. The adoption of new endodontic technology amongst Danish general dental practitioners. Int Endod J 2005;38:52-58.

9. Akpata ES. Endodontic treatment in Nigeria. Int Endod $J$ 1984;17:139-151. 
10. Main SW, Ng'ang'a PM. Root canal treatment and pulpotomy in Kenya. East Afr Med $J$ 1991;68:243-248.

11. Ahmed MF, Elseed Al, Ibrahim YE. Root canal treatment in general practice in Sudan. Int Endod $J$ 2000;33:316-319.

12. Al-Omari WM. Survey of attitudes, materials and methods employed in endodontic treatment by general dental practitioners in North Jordan. BMC Oral Health 2004;4:1.

13. Pitt FordTR, Stock CJR, Loxley HC, Watson RMG. A survey of endodontics in general practice in England. Br Dent $J$ 1983;83:222-224.

14. Christensen GJ. Using rubber dams to boost quality, quantity of restorative services. J Am Dent Assoc 1994;125:81-82.

15. Lynch CD, McConnell RJ. Attitudes and use of rubber dam by Irish general dental practitioners. Int Endod $J$ 2007;40:427-432.

16. Peciuliene V, Rimkuviene J, Aleksejuniene J, Haapasalo M, Drukteinis S, Maneliene R.Technical aspects of endodontic treatment procedures among Lithuanian general dental practitioners. Stomatologija 2010;12:42-50.

17. Whitten BH, Gardiner DL, Jeansonne BG, Lemon RR. Current trends in endodontic treatment: report of a national survey. J Am Dent Assoc 1996;127:1333-1341.

18. Byström A, Sundqvist G. Bacteriologic evaluation of the effect of 0.5 percent sodium hypochlorite in endodontic therapy. Oral Surg Oral Med Oral Pathol 1983;55:307-312.

19. Wadachi R, Araki K, Suda H. Effect of calcium hydroxide on the dissolution of soft tissues on the root canal wall. $J E n$ dod 1998;24:326-330.

20. Heling I, Chandler NP. Antimicrobial effect of irrigant combinations within dentinal tubules. Int Endod J 1998;31:8-14.

21. Saunders WP, Chestnutt IG, Saunders EM. Factors influencing the diagnosis and management of teeth with pulpal and periradicular disease by general dental practitioners. Part 2. Br Dent J 1999;187:548-554.

22. Whitworth JM, Seccombe GV, Shoker K, Steele JG. Use of rubber damand irrigant selection in UK general dental practice. Int Endod J 2000;33:435-441.

23. Hommez GM, Braem M, De Moor RJ. Root canal treatment performed by Flemish dentists. Part 1. Cleaning and shaping. Int Endod J 2003;36:166-173.

24. Bystrom A, Claesson R, Sundqvist G. The antibacterial effect of camphorated paramonochlorphenol, camphorated phenol and calcium hydroxide in the treatment of infected root canals. Endod Dent Traumatol 1985;1:170-175.

25. Sjögren U, Figdor D, Spangberg L, Sundqvist G. The antimicrobial effect of calcium hydroxide as a short-term intracanal dressing. Int Endod $J$ 1991;24:119-125.

26. Siers ML, Willemsen WL, Bronkhorst EM. Intracanal medication used in general dentistry. Ned Tijdschr Tandheelkd 2001;108:398-400.
27. Menezes MM, Valera MC, Jorge AO, Koga-Ito CY, Camargo $\mathrm{CH}$, Mancini MN. In vitro evaluation of the effectiveness of irrigants and intracanal medicaments on microorganisms within root canals. Int Endod $J$ 2004;37:311-319.

28. Rosenthal S, Spångberg L, Safavi K. Chlorhexidine substantivity in root canal dentin. Oral Surg Oral Med Oral Pathol Oral Radiol Endod 2004;98:488-492.

29. Ari H, Erdemir A. Effects of endodontic irrigation solutions on mineral content of root canal dentin using ICP-AES technique. J Endod 2005;31:187-189.

30. Chong BS, Pitt Ford TR. The role of intracanal medication in root canal treatment. Int Endod J 1992;25:97-99.

31. Lewis B. Formaldehyde in dentistry: a review for the millennium. J Clin Pediatr Dent 1998;22:167-177.

32. Kopczyk RA, Cunningham CJ, Abrams H. Periodontal implications of formocresol medication. J Endod 1986;12:567569.

33. Yamasaki M, Nakamura H, Kameyama Y. Irritating effect of formocresol after pulpectomy in vivo. Int Endod J 1994; 27:245-251.

34. Di Felice R, Lombardi T. Gingival and mandibular bone necrosis caused by a paraformaldehyde-containing paste. Endod Dent Traumatol 1998;14:196-198.

35. Ricucci D. Apical limit of root canal instrumentation and obturation, part 1. Int Endod J 1998;31:384-393.

36. Pratten DH, McDonald NJ. Comparison of radiographic and electronic working lengths. $J$ Endod 1996;22:173-176.

37. Hoer D, Attin T. The accuracy of electronic working length determination. Int Endod $J$ 2004;37:125-131.

38. Dummer PM, McGinn JH, Rees DG. The position and topography of the apical canal constriction and apical foramen. Int Endod J 1984;17:192-198.

39. Koch M, Eriksson HG, Axelsson S, Tegelberg A. Effect of educational intervention on adoption of new endodontic technology by general dental practitioners: a questionnaire survey. Int Endod $J$ 2009;42:313-21. Epub 2009 Feb 7.

40. Barbakow $F$. The status of root canal therapy in Switzerland in 1993. J Dent Assoc S Afr 1996;51:819-813.

41. Kaufman AY, Rosenberg L. Paresthesia caused by Endomethasone. J Endod 1980;6:529-531.

42. Erison RT, Yucel T, Kucukay S. Endomethasone root canal filling material in the mandibular canal: a case report. Oral Surg Oral Med Oral Pathol 1993;63: 343-345. 